Molecules 2004, 9, 650-657

molecules

ISSN 1420-3049

http://www.mdpi.org

\title{
Isolation and X-ray Crystal Structure of Tetrahydroisoquinoline Alkaloids from Calycotome Villosa Subsp. intermedia
}

\author{
Ali El Antri ${ }^{1}$, Ibtissam Messouri ${ }^{1}$, Mohamed Bouktaib ${ }^{1}$, Rachid El Alami ${ }^{2}$, Michael Bolte ${ }^{3}$, \\ Brahim El Bali ${ }^{1}$ and Mohammed Lachkar ${ }^{1, *}$
}

${ }^{1}$ Laboratoire d'Analyses, d'Essais et d'Environnement (L.A.E.E.), Département de Chimie, Faculté des Sciences "Dhar Mehraz", Université Sidi Mohamed Ben Abdellah, 30000 Fès, Morocco. Telefax: (+212) 55733171.

2 Département de Biologie, Faculté des Sciences "Dhar Mehraz", Université Sidi Mohamed Ben Abdellah, 30000 Fès, Morocco.

3 Institut für Organische Chemie, J. W. Goethe-Universität Frankfurt, Marie-Curie-Straße 11, 60439, Frankfurt/Main, Germany.

* Author to whom correspondence should be addressed; e-mail: $\underline{\text { mlachkar@ }, \text { hotmail.com }}$

Received: 18 December 2003; in revised form: 6 July 2004 / Accepted: 11 July 2004 / Published: 31 July 2004

\begin{abstract}
Two tetrahydroisoquinoline alkaloids were extracted from the alkaloid fraction of a methanol extract of the seeds of Calycotome Villosa Subsp. intermedia. Their structures were established as (R)-1-hydroxymethyl-7-8-dimethoxy-1,2,3,4-tetrahydroisoquinoline (1) and (S)-7-hydroxymethyl-2-3-dimethoxy-7,8,9,10-tetrahydroisoquinoline chloride (2) by spectroscopic techniques and X-ray diffraction analysis.
\end{abstract}

Keywords: Calycotome villosa (Poiret) Link Subsp. Intermedia, alkaloids, tetrahydroisoquinoline, spectroscopy, X-ray crystal structure determination.

\section{Introduction}

The isoquinoline alkaloids form one of the largest groups of compounds found in a variety of plant families [1-4]. With more than 50 different compounds found in nature, 1,2,3,4-tetrahydroisoquinoline 
(THIQ) and especially its derivatives with alkoxy substituents on the aromatic rings constitute the largest group within the simple isoquinoline alkaloids. These natural alkaloids are generally optically active compounds possessing important clinical applications such as analgesics, antihypertensives, smooth or skeletal muscle relaxants, antispasmodics, antitussives, antimalarials, narcotics and antipyretics [5]. It is worth noting that 1-substituted-THIQs, in which C-1 is a quaternary stereogenic centre, have been reported to display very interesting biological and pharmacological properties $[3,6,7]$. For instance, 1-methyl- and 1-phenyltetrahydroisoquinoline are involved in the treatment of Parkinson's and other nervous system diseases [8-10]. Previous phytochemical studies resulted in the isolation of two flavone glucosides from the flowers and leaves of Calycotome villosa Subsp. intermedia [11]. In continuation of our chemical investigations on this plant, we describe in this paper the isolation and unambiguous structure elucidation of two alkaloids, with the chemical formulae $\mathrm{C}_{12} \mathrm{H}_{17} \mathrm{NO}_{3}$ and $\mathrm{C}_{12} \mathrm{H}_{18} \mathrm{NO}_{3} \mathrm{Cl}$ and here labelled $\mathbf{1}$ and 2 , respectively.

\section{Results and Discussion}

The seeds of Calycotome villosa (Poiret) Link Subsp. Intermedia were extracted with hot methanol. The methanolic extract was purified in the usual way for the isolation of alkaloids [12]. Fractionation and silica gel column chromatography yielded the known compound $\mathbf{1}$ as the main constituent as well as the alkaloid 2 (see Scheme 1). Compound 1 was the most polar of all alkaloids found in the methanolic extract of Calycotome villosa. Alkaloids $\mathbf{1}$ and $\mathbf{2}$ were isolated in a crystalline form and completely characterized.

\section{Scheme 1.}
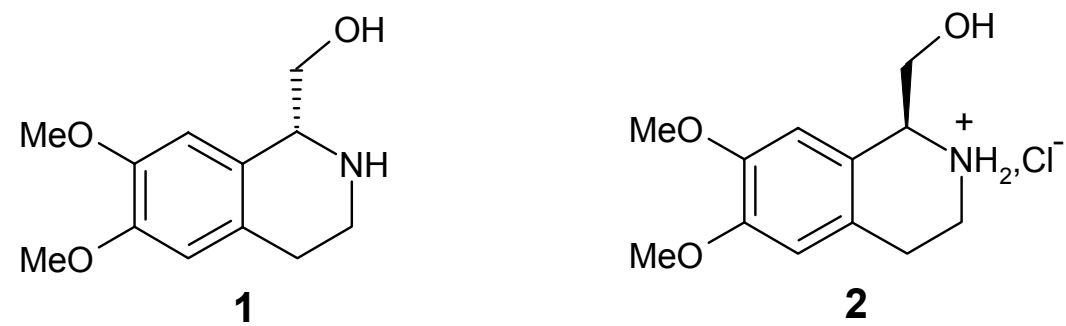

Alkaloid 1 was isolated as colorless crystals after recrystallization from methanol. It showed UV maxima at 235 and $278 \mathrm{~nm}$, IR bands at 3346, 2938, 2936, 1613, 1521, 1465, 1367, 1269, 1225, 1135 and $1055 \mathrm{~cm}^{-1}$. The ESI mass spectra afforded a molecular ion peak at $\mathrm{m} / \mathrm{z} 224[\mathrm{M}+\mathrm{H}]^{+}$, calculated for $\mathrm{C}_{12} \mathrm{H}_{17} \mathrm{NO}_{3}$. Its ${ }^{1} \mathrm{H}-\mathrm{NMR}$ spectrum showed aromatic protons as two singlets at $\delta 6.55(1 \mathrm{H}, \mathrm{s})$ and $6.56(1 \mathrm{H}, \mathrm{s})$. The two methoxy groups protons showed two singlets at $\delta 3.84(3 \mathrm{H}, \mathrm{s})$ and $3.85(3 \mathrm{H}, \mathrm{s})$. The four saturated cyclic ring protons of isoquinoline ring moiety $\left(\mathrm{NC}_{2} \mathrm{C}_{2}\right)$ showed signals as multiplets located around $\delta 2.63-2.69$ and 2.96-3.13. Its ${ }^{13} \mathrm{C}-\mathrm{NMR}$ spectrum showed four quaternary carbons, three methines, three methylenes and two methyl groups. Comparison of this data with the literature values [13-19] allowed identification of alkaloid $\mathbf{1}$ as the known compound (R)-1-hydroxymethyl-7-8-dimethoxy-1,2,3,4-tetrahydroisoquinoline (named calycotomine). 
Confirmation of the structure was obtained from X-ray diffraction of single crystals of 1 grown by slow evaporation from methanol. As expected, 1 has a tetrahydrosubstituted isoquinoline structure [2023]. The molecular structure and numbering scheme are shown in Figure 1. All bond lengths and angles are reasonable within experimental error (Table 1).

Figure 1. ORTEP view of $\mathbf{1}$ showing the atomic labeling scheme, with $H$ atoms removed for clarity. Thermal ellipsoids drawn at 50\% probability levels.

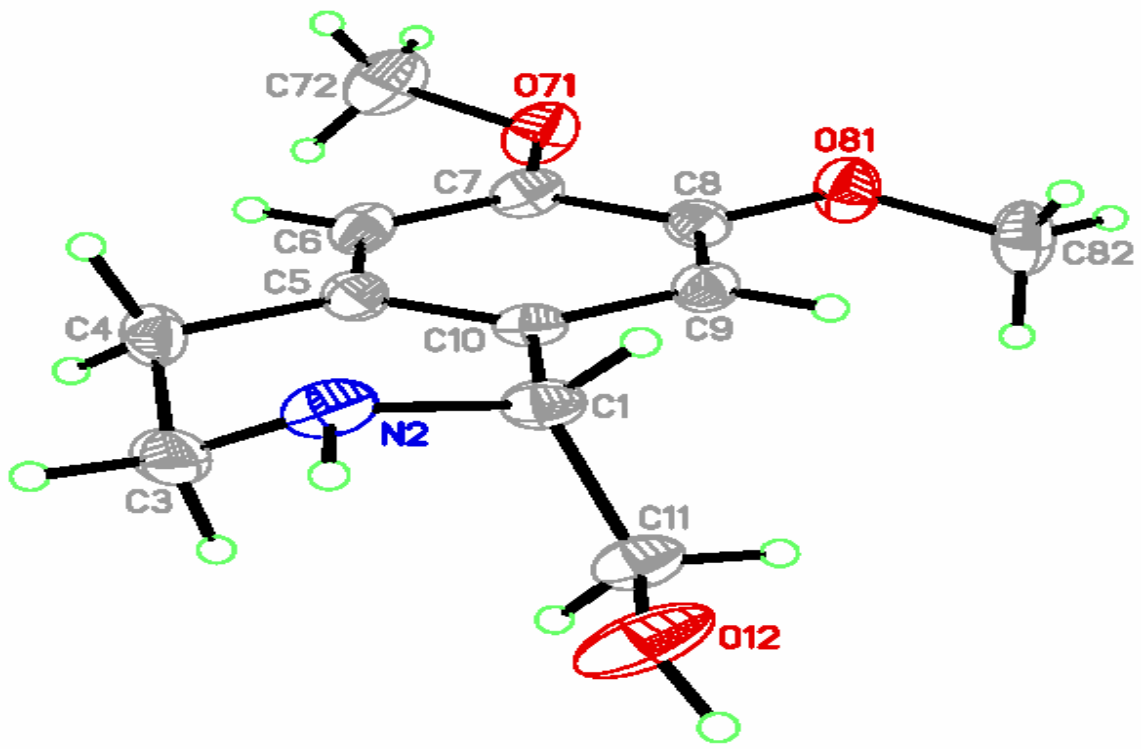

Table 1. Selected bond lengths and angles of 1.

\begin{tabular}{llll}
\hline Bond lengths $[\AA]$ & & & \\
C1 C10 & $1.5200(16)$ & $\mathrm{N} 2 \mathrm{C} 3$ & $1.4712(19)$ \\
C1 C11 & $1.5306(17)$ & $\mathrm{C} 3 \mathrm{C} 4$ & $1.5206(19)$ \\
C1 N2 & $1.4761(16)$ & $\mathrm{C} 4 \mathrm{C} 5$ & $1.5170(16)$ \\
Bond angles $\left.{ }^{\circ}\right]$ & & & \\
N2 C1 C10 & $110.36(11)$ & $\mathrm{C} 5 \mathrm{C} 4 \mathrm{C} 3$ & $110.70(11)$ \\
N2 C1 C11 & $112.29(10)$ & $\mathrm{C} 10 \mathrm{C} 5 \mathrm{C} 4$ & $120.70(11)$ \\
C10 C1 C11 & $111.91(10)$ & $\mathrm{N} 2 \mathrm{C} 3 \mathrm{C} 4$ & $108.33(10)$ \\
C3 N2 C1 & $112.61(10)$ & $\mathrm{C} 5 \mathrm{C} 10 \mathrm{C} 1$ & $122.56(10)$ \\
Torsion angles $\left[^{\circ}\right]$ & & & \\
C11 C1 N2 C3 & $-77.74(14)$ & $\mathrm{C} 1 \mathrm{~N} 2 \mathrm{C} 3 \mathrm{C} 4$ & $-69.21(14)$ \\
N2 C3 C4 C5 & $51.84(14)$ & $\mathrm{C} 3 \mathrm{C} 4 \mathrm{C} 5 \mathrm{C} 10$ & $-19.79(16)$ \\
C10 C1 N2 C3 & $47.86(14)$ & $\mathrm{C} 4 \mathrm{C} 5 \mathrm{C} 10 \mathrm{C} 1$ & $0.44(16)$ \\
$\mathrm{N} 2 \mathrm{C} 1 \mathrm{C} 10 \mathrm{C} 5$ & $-13.40(15)$ & $\mathrm{C} 11 \mathrm{C} 1 \mathrm{C} 10 \mathrm{C} 5$ & $112.42(13)$ \\
\hline
\end{tabular}


The $\mathrm{C} 5-\mathrm{C} 10$ aromatic ring is planar (r.m.s. deviation $=0.0094 \AA$ ). The methoxy groups at $\mathrm{C} 7$ and $\mathrm{C} 8$ atoms are slightly rotated around the $\mathrm{C} 7-\mathrm{O} 71$ and $\mathrm{C} 8-\mathrm{O} 81$ bonds (Figure 1), the dihedral angles between the plane of the aromatic ring and the planes defined by atoms $\mathrm{C} 7, \mathrm{O} 71, \mathrm{C} 72$ and $\mathrm{C} 8, \mathrm{O} 81$, $\mathrm{C} 82$ being respectively $12.7^{\circ}$ and $7.5^{\circ}$. The $\mathrm{C} 4$ atom lies almost in the plane of the aromatic ring, whereas atom $\mathrm{C} 1$ is slightly displaced from it (the deviation of atoms $\mathrm{C} 4$ and $\mathrm{C} 1$ from the ring plan are 0.003 and $0.045 \AA$, respectively). The $\mathrm{C} 1-\mathrm{C} 10$ and $\mathrm{C} 4-\mathrm{C} 5$ bonds are in the plane of the ring (angles with the normal to the plane are 91.0 and $90.6^{\circ}$, respectively), whereas the two remaining bonds, C8O81 and C7-O71, are slightly out of the plane (angles with the normal to the plane are 91.4 and $88.6^{\circ}$, respectively). As expected, the heterocyclic ring of tetrahydroisoquinoline adopts a half chair conformation.

Alkaloid 2 was also obtained as colorless crystals. It showed UV maxima at 234 and $270 \mathrm{~nm}$, IR bands at 3420, 3334, 2984, 2900, 1611, 1525, 1457, 1333, 1263, 1227, 1126 and $1067 \mathrm{~cm}^{-1}$ and MS fragment ions at $\mathrm{m} / \mathrm{z} 207,192,189,179,175,165,158,150$ and 147 , besides the molecular ion $(\mathrm{m} / \mathrm{z}$ 224). Its ${ }^{1} \mathrm{H}$ - and ${ }^{13} \mathrm{C}$-NMR spectral features were very similar to those of calycotomine (1), indicating the presence of the isoquionoline moiety in the molecule. Carbon resonances at $\delta 55.5,55.6$ and 61.5 confirm the presence of two methoxy groups and one methylene group.

However, the low basicity of $\mathbf{2}$, its low solubility in apolar organic solvents and its high solubility in water led us to think that alkaloid $\mathbf{2}$ was a salt. In an attempt to confirm this, an X-ray crystallographic study was performed. Suitable crystals for X-ray studies were obtained from methanol by slow evaporation. A view of $\mathbf{2}$ is shown in Figure 2, while selected molecular dimensions are reported in Table 2. Bond lengths and angles values fall in the expected range [23]. The independent unit of the crystal consist of the protonated main molecule and $\mathrm{Cl}^{-}$anion. As previously found for alkaloid 1, the main skeleton of $\mathbf{2}$ is formed by a tetrahydroisoquinoline moiety. The chloride ion $\mathrm{Cl}^{-}$interacts with the tetrahydroisoquinoline by means of weak H-bonds, with the strongest one [(N8-H8A...Cl1)] at $3.091 \AA$ A.

Figure 2. ORTEP view of (2) showing the atomic labelling scheme, with $\mathrm{H}$ atoms omitted for clarity. Thermal ellipsoids drawn at $50 \%$ probability levels.

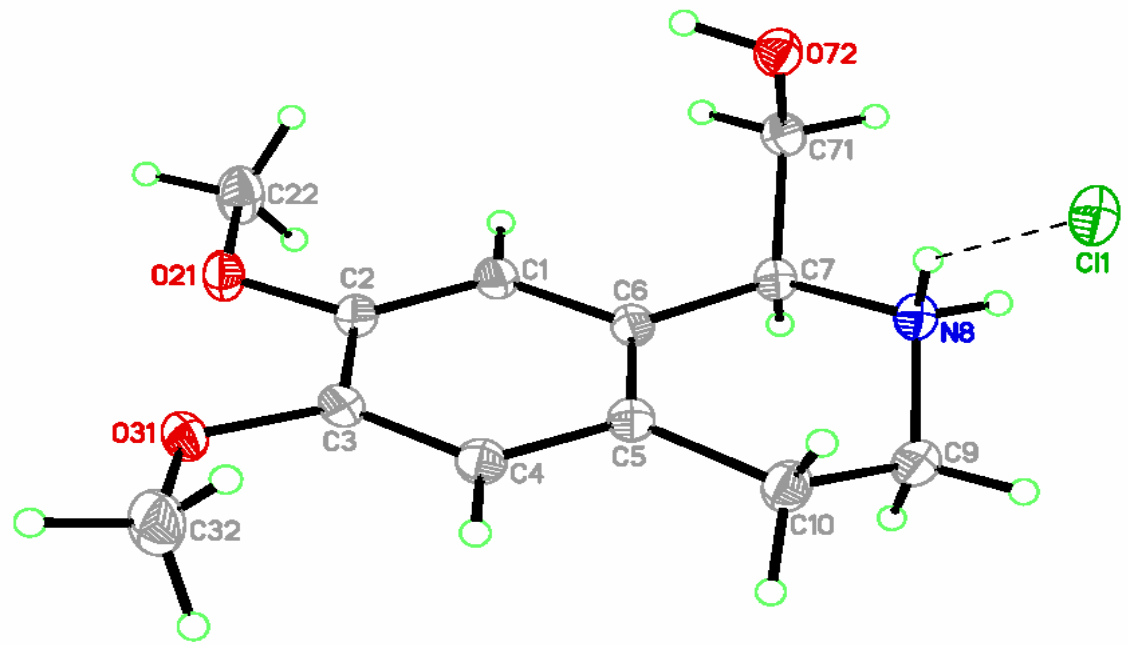


Table 2. Selected bond lengths and angles of 2.

\begin{tabular}{llll}
\hline Bond lengths $[\AA]$ & & & \\
C6 C7 & $1.5200(12)$ & C7 N8 & $1.4983(11)$ \\
C7 C71 & $1.5275(12)$ & N8 C9 & $1.4883(12)$ \\
C5 C10 & $1.5123(12)$ & C9 C10 & $1.5195(13)$ \\
Bond angles $\left.{ }^{\circ}\right]$ & & & \\
N8 C7 C6 & $109.89(7)$ & N8 C9 C10 & $108.46(7)$ \\
N8 C7 C71 & $107.23(7)$ & C5 C10 C9 & $111.10(8)$ \\
C9 N8 C7 & $112.95(7)$ & C6 C7 C71 & $114.65(7)$ \\
C5 C6 C7 & $122.27(8)$ & C6 C5 C10 & $122.02(8)$ \\
Torsion angles $\left[^{\circ}\right]$ & & & \\
C71 C7 N8 C9 & $173.06(7)$ & C6 C7 N8 C9 & $47.85(9)$ \\
C10 C5 C6 C7 & $-1.13(13)$ & C5 C6 C7 N8 & $-13.15(11)$ \\
C7 N8 C9 C10 & $-68.14(10)$ & C5 C6 C7 C71 & $-133.99(8)$ \\
N8 C9 C10 C5 & $49.53(10)$ & C6 C5 C10 C9 & $-17.45(12)$ \\
\hline
\end{tabular}

The crystallographic data obtained for the alkaloid 2 confirmed the previous spectroscopic attributions and the structure was assigned as (S)-7-hydroxymethyl-2-3-dimethoxy-7,8,9,10tetrahydroisoquinoline chloride.

\section{Conclusions}

Two alkaloids were isolated from the seeds of Calycotome Villosa Subsp. intermedia. Their structures were solved by X-ray analysis. Isolation and characterization of other alkaloids from this plant are currently under investigation.

\section{Acknowledgements}

The authors are grateful to Dr. C. Rolando, Equipe Polyphénols, UMR CNRS 8009, Université des Sciences et Technologies de Lille (France), for the ${ }^{1} \mathrm{H}$ - and ${ }^{13} \mathrm{C}-\mathrm{NMR}$ spectra and for the MS measurements, and Dr. H. Allouchi, Faculty of Pharmacy, Université de Tours, (France) for the optical rotation measurements.

\section{Experimental}

\section{General}

Melting points were measured in open capillary tubes in a Büchi 530 apparatus and are uncorrected. UV-visible spectra were obtained on a Varian Cary 3E spectrophotometer, and IR spectra 
were recorded on a Pye Unicam Perkin-Elmer spectrophotometer. ${ }^{1} \mathrm{H}$ - and ${ }^{13} \mathrm{C}$-NMR spectra were recorded in $\mathrm{CDCl}_{3}$ and DMSO-d $\mathrm{d}_{6}$ on a Bruker (Wiessembourg, France) AM 300 spectrometer (300 and $75 \mathrm{MHz}$, for ${ }^{1} \mathrm{H}$ - and ${ }^{13} \mathrm{C}$-NMR, respectively) and chemical shifts are given as $\delta$ values with TMS as an internal standard. $[\alpha]^{20}$ Dalues were measured using an ADP 220 polarimeter (Bellingham + Stanley LDT). ESI-MS data were obtained on a Quattro II tandem quadripole mass spectrometer (Micromass, Manchester, UK) fitted with an electrospray ionisation. Silica gel $\mathrm{GF}_{254}$ was used for TLC. Spots on chromatograms were detected under UV light $(254 \mathrm{~nm})$ and by Dragendorff's reagent. Column chromatography (CC) was carried out on silica gel 60 (70-230 mesh).

\section{Plant material}

Seeds of Calycotome Villosa Subsp. intermedia were collected from the aerial part of the plant in June 2001 and again in June 2002 from Zrireg valley, plateau of Tazzeka, area of Taza, Morocco.

\section{Extraction and isolation}

The powdered seeds (100 g) were first extracted with hexane for $24 \mathrm{~h}$ and then with methanol for $48 \mathrm{~h}$ using a Soxhlet apparatus. The methanolic solution was evaporated to dryness and the resulting crude extract was dissolved in a 5\% hydrochloric acid solution and extracted first with hexane and then with $\mathrm{CH}_{2} \mathrm{Cl}_{2}$. The aqueous solution was made basic to $\mathrm{pH} 10$ with concentrated ammonia and extracted three times each with $200 \mathrm{~mL}$ of $\mathrm{CH}_{2} \mathrm{Cl}_{2}$. The collected organic phases were dried over anhydrous sodium sulfate and evaporated under reduced pressure to give $1.75 \mathrm{~g}$ of the crude alkaloid extract. This was extracted with acetone and the residual product was dissolved in methanol $(25 \mathrm{~mL})$ and kept at room temperature overnight to give a crystalline powder. The precipitate obtained was filtered off and washed three times with $\mathrm{CH}_{2} \mathrm{Cl}_{2}$ to yield $0.15 \mathrm{~g}$ of a purified alkaloid 2 . The combined organic extract $\left(\mathrm{CH}_{2} \mathrm{Cl}_{2}+\mathrm{CH}_{3} \mathrm{COCH}_{3}\right)$ was concentrated and chromatographed on silica gel. The fraction eluted with $10 \%$ methanol in $\mathrm{CH}_{2} \mathrm{Cl}_{2}$ was concentrated to dryness to give pure compound $\mathbf{1}$ as colorless crystals $(0.5 \mathrm{~g})$. These products were recrystallized from methanol to afford crystals suitable for X-ray analysis.

(R)-1-hydroxymethyl-7-8-dimethoxy-1,2,3,4-tetrahydroisoquinoline [(R)-Calycotomine, 1]. Colorless crystals $(0.55 \mathrm{~g}), \mathrm{mp} 154-156{ }^{\circ} \mathrm{C} ;[\alpha]^{20}{ }_{\mathrm{D}}+46.1$ (c $\left.0.13, \mathrm{CH}_{3} \mathrm{OH}\right)$; UV-visible $\lambda_{\max }\left(\mathrm{CHCl}_{3}\right) \mathrm{nm}: 235$, 278; ${ }^{1} \mathrm{H}-\mathrm{NMR}\left(\mathrm{CDCl}_{3}\right): 2.63-2.69(3 \mathrm{H}, \mathrm{m}), 2.96-3.13(2 \mathrm{H}, \mathrm{m}), 3.62(1 \mathrm{H}, \mathrm{dd}, J=9.2,10.8 \mathrm{~Hz}), 3.75$ $(1 \mathrm{H}, \mathrm{dd}, J=4.2,10.8 \mathrm{~Hz}), 3.84(3 \mathrm{H}, \mathrm{s}), 3.85(3 \mathrm{H}, \mathrm{s}), 3.95(1 \mathrm{H}, \mathrm{dd}, J=4.2,9.2 \mathrm{~Hz}), 6.55(1 \mathrm{H}, \mathrm{s}), 6.56$ $(1 \mathrm{H}, \mathrm{s}) ;{ }^{13} \mathrm{C}-\mathrm{NMR}\left(\mathrm{CDCl}_{3}\right): 29.1\left(\mathrm{C}_{4}\right), 38.9\left(\mathrm{C}_{3}\right), 55.8\left(\mathrm{CH}_{3}\right), 56.0\left(\mathrm{CH}_{3}\right), 56.1\left(\mathrm{C}_{1}\right), 64.1\left(\mathrm{CH}_{2}\right), 109.2$ $\left(\mathrm{C}_{9}\right), 112.0\left(\mathrm{C}_{6}\right), 127.1\left(\mathrm{C}_{5}\right), 127.7\left(\mathrm{C}_{10}\right), 147.4\left(\mathrm{C}_{8}\right), 147.7\left(\mathrm{C}_{7}\right)$; ESI-MS m/z $=224[\mathrm{M}+\mathrm{H}]^{+}$.

(S)-7-hydroxymethyl-2-3-dimethoxy-7,8,9,10-tetrahydroisoquinoline chloride (2). Colorless crystals (0.15 g); mp 202-204 ${ }^{\circ} \mathrm{C}$; $[\alpha]^{20}{ }_{\mathrm{D}}+29.2$ (c 0.24, $\left.\mathrm{CH}_{3} \mathrm{OH}\right)$; UV-visible $\lambda_{\max }(\mathrm{MeOH}) \mathrm{nm}: 234,270$;

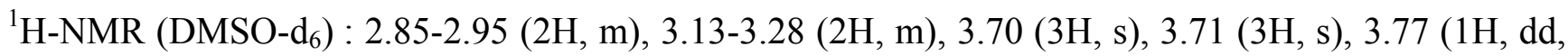
$J=8.0,10.8 \mathrm{~Hz}), 3.96(1 \mathrm{H}, \mathrm{dd}, J=3.5,10.8 \mathrm{~Hz}), 4.33(1 \mathrm{H}, \mathrm{dd}, J=3.5,8.0 \mathrm{~Hz}), 6.78(1 \mathrm{H}, \mathrm{s}), 6.85$ 
$(1 \mathrm{H}, \mathrm{s}), 9.49(2 \mathrm{H}, \mathrm{s}) ;{ }^{13} \mathrm{C}-\mathrm{NMR}\left(\mathrm{DMSO}_{\mathrm{d}}\right): 24.5\left(\mathrm{C}_{10}\right), 38.4\left(\mathrm{C}_{9}\right), 55.5\left(\mathrm{CH}_{3}\right), 55.6\left(\mathrm{CH}_{3}\right), 55.7\left(\mathrm{C}_{7}\right)$, $61.5\left(\mathrm{CH}_{2}\right), 109.9\left(\mathrm{C}_{1}\right), 111.8\left(\mathrm{C}_{4}\right), 121.4\left(\mathrm{C}_{5}\right), 124.7\left(\mathrm{C}_{6}\right), 147.5\left(\mathrm{C}_{2}\right), 148.3\left(\mathrm{C}_{3}\right) ; \mathrm{ESI}-\mathrm{MS} \mathrm{m} / \mathrm{z}=224$ $\left[\mathrm{M}-\mathrm{Cl}^{-}\right]^{+}$.

X-ray Crystal Structure Determination [24]

Colorless single crystals of $\mathbf{1}$ and $\mathbf{2}$ suitable for X-ray structure analysis were obtained by slow evaporation of a methanol solution. Table 3 summarizes the crystal and experimental data. The data for both crystals have been collected on a STOE IPDS II two-circle-diffractometer using a $\mathrm{Mo}_{\mathrm{K} \alpha}$ radiation $(\lambda=0.71073 \AA)$. An empirical absorption correction was applied [25]. The structures were solved with direct methods [26] and refined with full-matrix least squares techniques [27]. All non-H atoms were refined with anisotropic displacement parameters. $\mathrm{H}$ atoms were located in an electron difference map and refined using a riding model. No decay of intensity was observed.

Table 3. Crystal and experimental data of $\mathbf{1}$ and $\mathbf{2}$

\begin{tabular}{|c|c|c|}
\hline & (1): $\mathrm{C}_{12} \mathrm{H}_{17} \mathrm{NO}_{3}$ & (2): $\mathrm{C}_{12} \mathrm{H}_{18} \mathrm{ClNO}_{3}$ \\
\hline Measurement Temp. (K) & $173(2)$ & $100(2)$ \\
\hline $\mathrm{M}(\mathrm{g} / \mathrm{mol})$ & 223.27 & 259.72 \\
\hline Symmetry (S. G., Z) & Monoclinic $\left(\mathrm{P} 2_{1}, 2\right)$ & Monoclinic $\left(\mathrm{P} 2_{1}, 2\right)$ \\
\hline Cell parameters $\left(\AA,^{\circ}\right)$ & $\begin{array}{l}a=5.9832(6) \\
b=10.4332(12) \\
c=9.4578(9) \\
\beta=102.876(7) \\
V=575.55(10) \AA^{3}\end{array}$ & $\begin{array}{l}a=7.6210(6) \\
b=7.7365(5) \\
c=11.0750(9) \\
\beta=92.487(7) \\
V=652.37(9) \AA^{3}\end{array}$ \\
\hline $\mathrm{d}_{\text {cal. }}\left(\mathrm{g} \cdot \mathrm{cm}^{-3}\right)$ & 1.288 & 1.322 \\
\hline Crystal dimensions (mm) & $0.47 * 0.17 * 0.11$ & $0.38 * 0.34 * 0.14$ \\
\hline $\mathrm{F}(000)$ & 240 & 276 \\
\hline$\mu_{(\mathrm{Mo} \mathrm{K} \alpha)}\left(\mathrm{mm}^{-1}\right)$ & 0.092 & 0.290 \\
\hline $\mathrm{T}_{\min .} / \mathrm{T}_{\max }$ & $0.9579 / 0.9899$ & $0.8979 / 0.9606$ \\
\hline $\begin{array}{l}\text { Total measured reflexions } \\
\text { / Refined }[\mathrm{I}>2 * \sigma(\mathrm{I})]\end{array}$ & $9590 / 2341$ & 14717 / 3870 \\
\hline $\mathrm{R} / \mathrm{Rw}\left(\right.$ on $\mathrm{F}^{2}$ ) & $0.0303 / 0.0724$ & $0.0234 / 0.0632$ \\
\hline
\end{tabular}

\section{References and Notes}

1. Bently, K. W. The Isoquinoline Alkaloids; Harwood Academic Publishers: Amsterdam, 1998.

2. Shamma, M. The Isoquinoline Alkaloids. Chemistry and Pharmacology; Academic Press: New York, 1972; Vol. 25. 
3. Herbert, R. B. In The Chemistry and Biology of Isoquinoline Alkaloids; Philipson, J. D., Roberts, M. F.; Zenk, M. H., Eds; Springer Verlag: Berlin, Heidelberg, New York, Tokyo, 1985; p. 213.

4. Shamma, M., Moniot, J. L. Isoquinoline Alkaloid Research 1972-1977; Plenum Press: New York, 1978.

5. Kitamura, M.; Hsiao, Y.; Ohta, M.; Tsukamota, M.; Ohta, T.; Takaya, H.; Noyori, R. J. Org. Chem. 1994, 59, 297.

6. Locher, C.; Peerzada, N. J. Chem. Soc., Perkin Trans. 1 1999, 179.

7. He Y.; Nikulin, V. I.; Vansal, S. S.; Feller, D. R.; Miller, D. D. J. Med. Chem. 2000, 43, 591.

8. Taniyama, D.; Hasegawa, M.; Tomioka, K. Tetrahedron: Asymmetry 1999, 10, 221.

9. Gray, N. M.; Cheng, B. K.; Mick, S. J.; Lair, C. M.; Contreras, P. C. J. Med. Chem. 1989, 32, 1242.

10. Wanner, K. Th.; Beer, H.; Höfner, G.; Ludwig, M. Eur. J. Org. Chem. 1998, 2019.

11. El Antri, A.; Messouri, I.; Chendid Tlemcani, R.; Bouktaib, M.; El Alami, R.; El Bali, B.; Lachkar, M. Molecules 2004, 9, 568.

12. Dalton, D. R. The Alkaloids - The Fundamental Chemistry, a Biogenetic Approach; Marcel Dekker: New York, 1979.

13. Brossi, A.; Burkhardt, F. Helv. Chim. Acta 1961, 44, 1558.

14. Tosun, F.; Tanker, M.; Ozden, T.; Tosun, A. Planta Med. 1987, 53, 499.

15. White, E. P. New Zealand J. Sci. Tech. 1944, 25B, 137.

16. Czarnocki, Z. J. Chem. Res. (S) 1992, 334.

17. Czarnocki, Z. J. Chem. Res. (M) 1992, 2801.

18. Morimoto, T.; Suzuki, N.; Achiva, K. Tetrahedron: Assymetry 1998, 9, 183.

19. Pedrosa, R.; Andrés, C.; Iglesias, J. M. J. Org. Chem. 2001, 66, 243.

20. Czarnocki, Z.; Maurin, J. K. Acta Cryst. 1993, C49, 1992.

21. Czarnocki, Z.; Maurin, J. K.; Winnicka-Maurin, M. Acta Cryst. 1994, C50, 1779.

22. Maurin, J. K.; Czarnocki, Z.; Paluchowska, B. Acta Cryst. 1996, C52, 953.

23. Allen, F. M.; Kennard, O.; Watson, D. G.; Btammer, L.; Orpen, A. G.; Taylor, R. J. Chem. Soc., Perkin Trans. 2 1987, S1.

24. CCDC 223477 and 223478 contain the supplementary crystallographic data for compounds $\mathbf{1}$ and 2. These data can be obtained free of charge via www.ccdc.cam.ac.uk/conts/retrieving.htlm (or from the CCDC, 12 Union Road Cambridge CB2 1EZ, UK; fax: +44 1223 336033; e-mail: deposit@ccdc.cam.ac.uk).

25. Blessing, R. H. Acta Cryst. 1995, A51, 33.

26. Sheldrick, G. M. Acta Cryst. 1990, A46, 467.

27. Sheldrick, G. M., SHELXL-97, Program for the refinement of crystal structures; University of Göttingen: Göttingen, (Germany), 1997.

Sample availability: Samples of compounds $\mathbf{1}$ and $\mathbf{2}$ are available from the authors and MDPI.

(C) 2004 by MDPI (http://www.mdpi.org). Reproduction is permitted for noncommercial purposes. 